\title{
Testing and Evaluation of a Smart Irrigation System Towards Smart Landscaping in UAE
}

\author{
Fatma Al Sulaimani, Bassam Abu-Hijleh \\ Sustainable Design of the Built Environment, Faculty of Engineering \& IT, The British University in Dubai, Dubai, The United Arab Emirates
}

Correspondence Author: Bassam Abu-Hijleh, The British University in Dubai, PO Box 345015, Dubai-UAE

Received date: 12 May 2019, Accepted date: 24 September 2019, Online date: 25 October 2019

Copyright: (C) 2019 Fatma Al Sulaimani, et al. This is an open-access article distributed under the terms of the Creative Commons Attribution License, which permits unrestricted use, distribution, and reproduction in any medium, provided the original author and source are cre dited.

\begin{abstract}
The population is growing drastically causing an increase in urban development and landscape expansion, which as a result increase the demand for water. In the GCC region, water is becoming a threat to the impact of climate change and the lack of water resources. The main source of water is mostly desalination plants. Current irrigation systems are not suited to solve the issues of water in the near future. This study is an evaluation of the impact of innovative technology, especially the use of the Internet of things (IoT) on the performance of a typical irrigation system currently used in Dubai, UAE. A field experiment was conducted to measure the selected parameter: Water consumption and irrigation management. This means a profound measurement on the impact of integrating soil moisture sensor into the current irrigation system is evaluated to assess the impact this integration. The core methodology used in this research was the field experiment; statistical analysis was also required to validate the results obtained on site. The results observed from the experiment were that the use of smart irrigation system (SIS) has environmental advantages in the long term especially in terms of water consumption and irrigation management. Less water is required to irrigate when the soil is saturated enough causing a healthier plants growth. The outcomes of the use of SMS have shown better results in water conservation, $21 \%$, and $26 \%$ decrease in water consumption for the months of September and October, respectively.
\end{abstract}

Keywords: Smart irrigation, water savings, UAE

\section{INTRODUCTION}

Humans have always looked into agriculture as the main source of food production. Since the existence of humanity on earth, they have relied on crops cultivation for food security. With human civilization, they began to examine the aesthetic part of the green spaces by integrating man-made features with natural resources. These green spaces evolved from agriculture to horticulture, including public urban spaces, private gardens, and parks, all the way to the street and interchanges. The innovation of green spaces has also offered an opportunity to move vertically by introducing the concepts of green walls, hanging planters, and vertical gardens. Urban green spaces not only used as a source of food production but also space where greenery exists for relaxation, meditation, social gathering and a purification buffer from the urban cities. The increase of population and urbanization have put so much pressure into the need for more agricultural and landscape areas. Yet, as a result of climate change and global warming, water availability is becoming a critical factor impacting the efficiency of agriculture and landscape all over the world. Irrigation practices have gone through a massive development since the urbanization. However, the need for innovative and smart practices can be the ultimate solution.

The landscape and the agriculture of the United Arab Emirates is an embodiment of the rapid transformation the tiny desert oasis has gone through in the last few decades. The green pastures delicately and aesthetically balanced in the urban development; preserving and maintaining the mesmerizing symbols of the traditional way of life and culture, and above all traces of flourishing agriculture reflects how far the country tackled the harsh climate and advanced even in the backdrop of relatively low rainfall and compounding water scarcity. The water scarcity and the harsh desert climatic conditions make the land infertile [1-3] warn that the pace of the water demand will increase as the population increases in the GCC nations, as the need for the food security will be greater. Figure 1 highlights the low rate of the use of renewable sources of water in the GCC nations compared to the non-renewable sources of water. Oman is the only state with a high percentage of renewable water sources while the other countries in the union are highly dependent on the non-renewable water sources such as desalination plants and treated wastewater for their water use. 
Citation: Fatma AlSulaimani, et al., 2019. Testing and Evaluation of a Smart Irrigation System Towards Smart Landscaping in UAE. Journal of Applied Sciences Research., 15(5): 13-17. DOI: 10.22587/jasr.2019.15.5.3

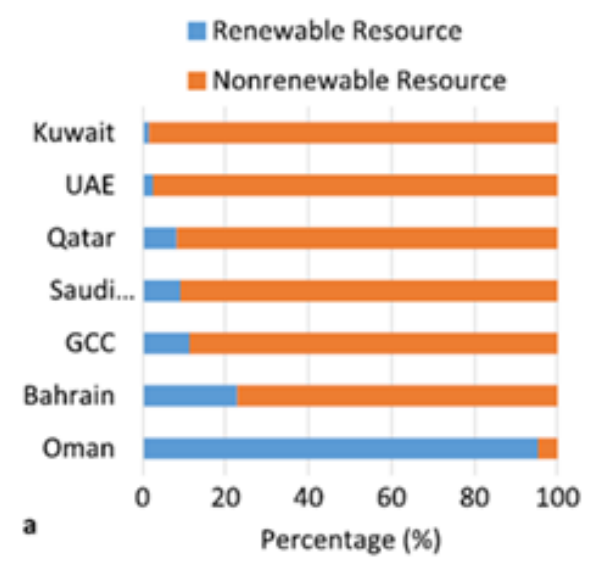

Figure 1: Renewable and nonrenewable resources of water consumption in GCC Countries (2013) [3]

The use of sprinklers, sprayer, drippers and many other technologies. The lack of efficiency of the current irrigation practices makes the shift towards a more productive and equitable irrigation system more imperative. Water efficiency is crucial to sustaining the sources and this should be properly quantified. The present irrigation systems are unable to cater to this demand and the new irrigation applications will help us to predict the amount of water needed for certain plants during a particular period of time and this can bring much-needed efficiency to the irrigation system while boosting the utility of the water used. The productivity of the plants and crops is also dependent on the amount of water it receives. Too much water can be as damaging as too little water thus accurately providing the required level of irrigation can enhance productivity in addition to saving water. Smart irrigation systems that utilize sensors, actuators and other innovative technologies can be used to achieve this goal.

The efficient use of the water in agriculture will help the arid regions with low precipitation to tide over the difficulty of bypassing production of the food grains. Navarro-Hellin et al. [4] in their article titled, "A decision support system for managing irrigation in agriculture" supports how the automatic Smart Irrigation Decision Support System (SIDSS), can manage the irrigation in agriculture. The SIDSS approach has been validated on three commercial plantations in the South East of Spain on the citrus trees crops. The expert agronomists have examined the soil, plant, and atmosphere in the region extensively to arrive at and manage the irrigation requirement of the crops and sensors were used to gather and measure the information by way of a set of variables. Navarro-Hellin et al. [4] further state that sensors will help in discerning the water surplus of the plants and soil, and thereby the right level of the water requirement can be automatically maintained using this SIDSS system. The continuous soil measurement to support the climatic parameters and to predict the right level of irrigation needs of the crops is the hallmark of this smart irrigation system and can be customized in accordance with the local perturbations

Food security, economic pricing, low unemployment and healthy socio-economic development combined with increased resources for industrial units are the advantages of a well-established and sustainable agricultural sector. But efficient irrigation and agriculture in arid and semi-arid regions is a challenge not to mention the detrimental impact of the intensive irrigation practices on the ecology and environment. Todorovic, Mehmeti, and Scardigno [5] argue that achieving the eco-efficiency by way of innovative water management process and technologies. The major environmental challenges of the intensive irrigation practices for agriculture are depletion of the ground and the surface water, climate change and the eutrophication. A study conducted on the Sinistra Ofanto irrigation scheme in Southern Italy in order to understand and measure the environmental performance using a set of mid-point environmental impact categories, while taking into consideration economic performance as well, revealed the major environmental challenges [5]. The depletion of the freshwater due to excessive groundwater pumping and surface water use; climate change arising from the increased use of the fertilizers and emission from the diesel combustion; and the eutrophication due to the result of excessive application of the nitrogen $(\mathrm{N})$ and phosphorus $(\mathrm{P})$ fertilizers are common in these geographical areas. Eco-efficiency and modern technology-based water management can reduce the impact on the environment .

Smartphone and applications have permeated all aspects of our life and irrigation efficiency and water conservation is not exempt from this as well. Bartlett et al. [6] provide us with a glimpse of how the smartphone app and technology has been adopted and embraced for finding out the solution to the water shortage in Colorado. The vibrant crops production is made possible with the help of the irrigation in the semi-arid western United States. The agricultural producers supplement the soil moisture with the irrigation in addition to the surface and groundwater in Colorado [6]. The population growth and the drought made the water very scarce in the semi-arid region of the Western part of United States and the effective and productive use of the water and irrigation is important to sustain the production of the agricultural produce. The Colorado state university took the initiative and provides the farmers, research scientists, and the irrigation managers a tool to find the solution for the water shortage. If the technology is not efficient, accessible and economical, it is a disincentive for the adoption by the common farmers. The smartphone app WISE provides an easy platform for the users to access and upload information where there is cellular coverage. WISE provide the details of the evapotranspiration-based irrigation scheduling based on the soil water balance method and data queries from the Colorado Agricultural Meteorological Network and Northern Colorado Water Conservation District weather stations [6]. The ability of the app users to find out quickly the soil moisture deficit, weather measurements can significantly help in the irrigation management of their crops .

Ye et al. [7] explore the possibility of integrating the latest innovation of the internet of things in water quality monitoring. Using intelligent perception, intelligent simulation, diagnosis and warning, the water quality and the pollution level at the source level can be diagnosed and monitored. The real-time active sensing layer, smart decision layer and an interconnecting layer of water information is essential to this new architecture of smart water initiative based on the internet of things and is generally called as the hierarchy framework. There is a technical system and function framework as well in this architecture to allow it to smoothly function and deliver the objectives [7]. The multi-carrier network consisting of real-time transporting, intelligent storage of mass data and diagnosis of the water security risk are involved in the technical system while the function framework includes the modules such as the intelligent sensing, intelligent simulation and the intelligent diagnosis coupled with early warning and intelligent regulation. Shahanas and Sivakumar [8] further argue for the importance of the internet and how it has revolutionized the world and mentions the advancement by pointing out the Internet of Things and the increasing role it plays in our daily life. The water is the most important ingredient for the survival of human beings and how smart water management can help in the development and running of the so-called smart cities popping up globally. The emerging technology and the Internet of Things are cost-effective to be adopted by the smart cities so as to build and efficiently use the smart water management for the future in order to ensure the sustainability of the water resources and reduce the waste [8] .

Technology-based irrigation and water management systems are best exemplified in the study titled, "Comparison of irrigation automation algorithms for drip-irrigated apple trees". Osroosh et al. [9] studied irrigation scheduling by developing and evaluating seven algorithms of irrigation scheduling. The plant/thermal-based strategies of the time; Temperature Threshold and Crop Water Stress Index were included in this as well. Using a wireless control and monitoring system, irrigation water delivery was automatically scheduled in an apple orchard. The weather and the plant-based algorithms were found to deliver enough irrigation water to the apple trees and thereby avoided the stress. The soil-based approach failed to deliver enough water to the trees leading to water stress and stunted growth [9]. Automatic irrigation on the drip-irrigated apple trees proved to be efficient and can help in the water use efficiency, increased production and above all reduced cost of production. The reduction in the energy cost of pumping. Improved quality of the products is some of the other advantages of this irrigation scheduling algorithms .

Technology-based irrigation has huge advantages and is more efficient compared to time-based irrigation. The rain sensor, soil water sensor, and the evapotranspiration controller help in the water savings by way of the water volume applied to the soil and the water volume drained away from the soil and the plants. In a pilot study involving four types of irrigation treatment namely the automatic timer, automatic timer with rain sensors, automatic times with SWS and 
ET controller, the automatic timer was found to have used significantly more amount of water compared to other three treatments [10]. In spite of the existence of the strict rules and regulations for protecting the water bodies, the water quality in many states is being degraded continuously. Fertilizers used to maintain and increase the aesthetic beauty of the turf and landscape plants in the urban centers and nutrients such as Nitrogen is increasingly applied to meet the plant requirements. The excessive rain and the irrigation carry this nutrient by leachate or runoff to water bodies and may exceed the natural capacity of the water source resulting in pollution. This can be easily prevented if we adopt the technology-based irrigation instead of the time-based irrigation and help in both the efficient use of water conservation and reducing the pollution of the ground and the surface water .

The use of smart sprinkler systems has been increasingly used in firefighting and irrigation in many parts of the world. The design and the fabrication of the water sprinkler system plays a greater role in determining the efficiency of water irrigation and use [11]. A survey performed on the application of the water sprinklers in Bangladesh and abroad by the authors has revealed that designing and developing a rotary type automated water sprinkler with the help of the Quality Function Deployment is very efficient, safe and easy to use for a variety of applications. Al Ghobari and El Marazky [12] argue in their article titled, "Effect of smart sprinkler irrigation utilization on water use efficiency for wheat crops in arid regions" that the smart irrigation is the best solution for the scheduling of the irrigation and to quantify the water required by the plants and crops. The control irrigation system that is scheduled based on data from automatic weather station while the Smart Irrigation System was implemented and tested on the sprinkler irrigation system. The latter has been proved to be very effective in saving the water and irrigation water use efficiency. The extreme irrigation does not increase the yield or bring optimal economic benefit leading the team that undertook the study to conclude that smart irrigation based on the latest technology and the sprinkler irrigation is suitable for the agricultural crops and achieving the water use efficiency [12].

Ensuring the sustainability of our future smart cities is a top priority for the planners and decision makers. These cities are energy guzzlers with the possible mobilization of different and varied knowledge centers, information technology and communication technology helping them to feed and maintain the innovation hub for the future [13]. The cost of production, transportation and the logistics involved in food production are on the rise as well and supporting the everincreasing urban population and their water and energy use is a challenge and nightmare for all authorities concerned. dos Santos [13] suggests Aquaponics as an integrated system suitable for the prospective smart cities. This new agricultural system encompasses all the activities and supply chain right from the producers to the consumers in addition to ensuring the organic supply of fresh produce free from the pesticides and chemicals. The smart cities do not mean the existence of Information and Communication Technology alone, rather an innovation hub supporting all aspects of the life of humans. Taking care of the food production and logistics, the smart cities will be able to strengthen the socio-economic progress as well.

\section{Objectives}

The aim of this study is to assess the potential water savings using smart irrigation compared to the current irrigation systems used in Warsan Nursery in Dubai-UAE, Sprayer, and Dripper. This was achieved by studying the existing irrigation systems used in Dubai by looking into various case studies that measure the impact of the current practices. Exploring the prevailing irrigation technologies available in the market and suitable for the region that will enhance irrigation water usage. Identifying the different parameters affecting the usage of a conventional irrigation system in Dubai. Integrating irrigation smart features in the landscape and agriculture of Dubai. Evaluating the performance of smart system through field experiment and compare that to the performance of the existing irrigation systems.

\section{Research Methodology}

A combination of field experiments, complemented by simple calculation and statistical analysis, were conducted at the Warsan Nursery of Dubai Municipality, Dubai-UAE during the summer of 2017. Table 1 shows the metrological data measured during the field experiment; there was no rain during this period. The site is already cultivated and it should be noted that the two irrigation methods used are; drip irrigation for the shrubs shown and sprayers used for the field grass. Figure 1 shows the plot area used in the experiment.

Table 1: Metrological data of the experiment site

\begin{tabular}{|c|c|c|c|c|}
\hline Month & Temp, Max $\left({ }^{\circ} \mathrm{C}\right)$ & Temp, Min $\left({ }^{\circ} \mathrm{C}\right)$ & Humidity $(\%)$ & Average Wind speed $(\mathrm{km} / \mathrm{h})$ \\
\hline July & 41 & 35 & 38 & $10 \mathrm{~km} / \mathrm{h}$ \\
\hline Aug & 43 & 34 & $18 \%$ & $11 \mathrm{~km} / \mathrm{h}$ \\
\hline Sep & 41 & 32 & $34 \%$ & $16 \mathrm{~km} / \mathrm{h}$ \\
\hline Oct & 37 & 29 & $60 \%$ & $21 \mathrm{~km} / \mathrm{h}$ \\
\hline
\end{tabular}

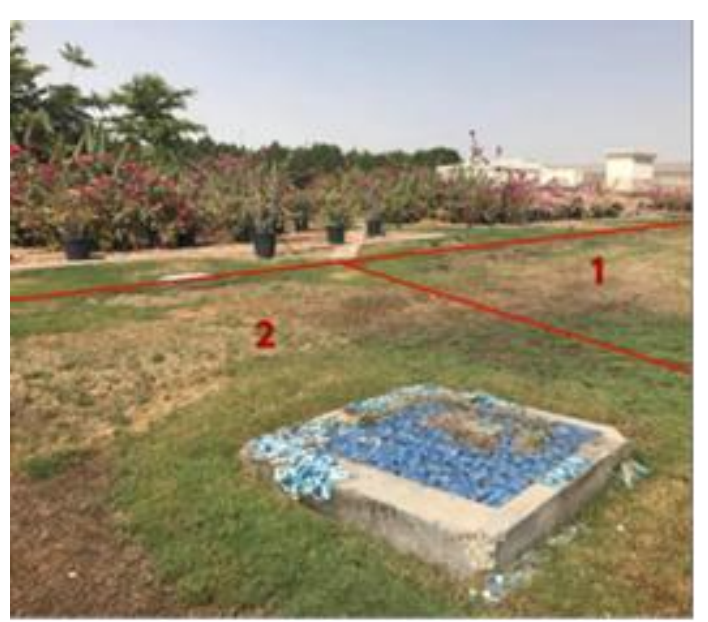

Figure 1: Selected plot for the field experiment

The picture in figure 1 was taken before the integration of the Smart Irrigation System (SIS). The condition of the grass as shown indicates very low maintenance in some area with grass disease covering some parts, due to high temperature, low water pressure and a probability of soil disturbance. Therefore, action was required to maintain the grass and manage the water pressure of the sprayer nozzles prior to the field experiment. The site was divided into 2 plots, both of which included a combination of drip and spray type irrigations systems. The SMRT-Y Soil Moisture Sensor Kit [14] Smart Irrigation System was integrated with the irrigation systems in plot 1; the results of plot 1were served as the baseline data against which the results of plot 1 were compared. Figure 2 shows the installation process of the SMRT-Y kit's main components.

The SMRT-Y system used in this research utilizes a smart soil moisture sensor that measures the amount of soil moisture. The measurements of this sensor are used to assess the irrigation requirements and duration thus ensuring that the plants receive the needed amount of water when needed while avoiding under or over-irrigating the plot. This approach should result in water consumption saving when compared to the current timer-based irrigation strategy. 

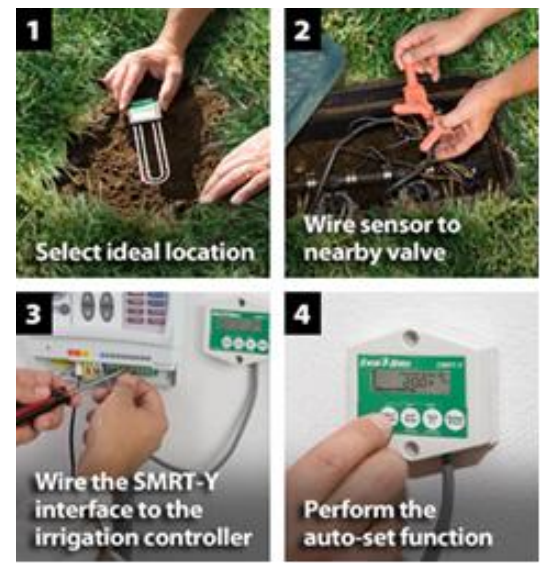

Figure 2: The installation of SMRT-Y Soil Moisture Sensor Kit [14]

\section{Results and Discussion}

The main data collected was the water consumption used for the irrigation of the shrubs and the grass areas for the two technologies employed; the old timerbased irrigation and the new soil-moister sensor-based irrigation approach. The environmental aspects of the study will be looked upon by evaluating the primary water flow of each configuration and the healthier growth of the plants by examining the difference of the leaves color along with examining the roots of the shrubs and the brightness of its leaves color. Proper irrigation management results in preserving the natural environment and its sustainability. Energy is also a parameter to consider for future study, yet it has not been considered for this field experiment due to time limitation and availability of resources. When using the CIS irrigation systems; dripper and sprayer irrigation are operated manually onsite by a certain number of labors. The main pipeline of water quantity and timing are monitored and recorded via a controller and the main STP in Sewerage and irrigation network department by Dubai Municipality. Yet, the sub-pipelines are regulated on site. The daily irrigation schedules vary on daily basis. For instance, some days it will be irrigated early morning, other days it can be later in the afternoon. The variations in irrigation schedules are not based on weather condition, soil water content or plantation need but the decision of the labors on site. Table 2 shows the water requirement as per the existing plants used for this research study in the months of July through October

The duration of the current irrigation system can be divided or irrigated at once. For instance, the 20 minutes set for the grass can be irrigated as 10 minutes in the morning and 10 minutes in the evening. The same thing with the Bougainvillea, 45 minutes can be divided as 20 minutes in the morning and 25 minutes in the evening. The goal set for the controlled irrigation system (CIS) that the plants get its full water requirement set for each type as shown in Table 2 regardless of the moister content of the soil. The effect of the current controlled irrigation system (dripper and sprayer) scheduling on the plant's growth were investigated and observed by examining the continuous growth of the plants throughout the experiment and the minimization of the fungus disease in the grass area. Growth quality for both; field grass and shrubs are shown in figure 2 due to harsh climatic condition and unmanaged irrigation scheduling, the grass has shown negative germination.
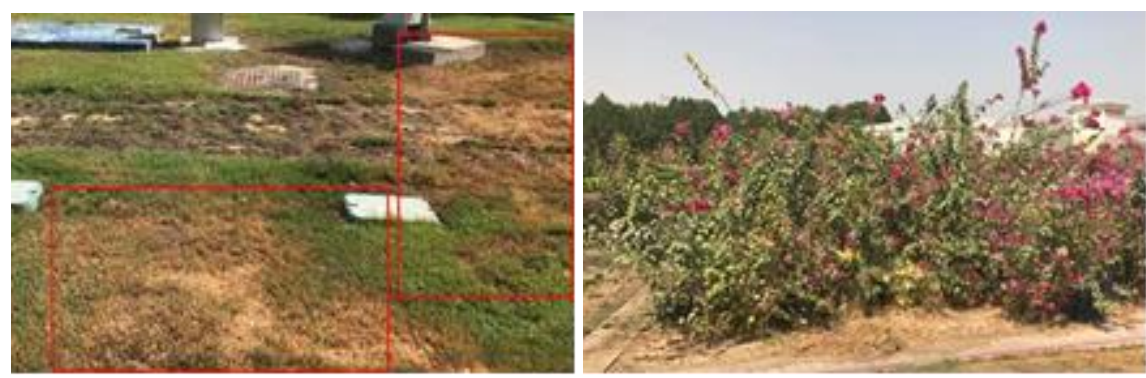

Figure 2: Field grass showing fungus disease spreading in many parts of the grass (Top) and Bougainville shrubs (Bottom)

Unlike the constant irrigation rates of the CIS system, the smart irrigation system (SIS) varied the irrigation rates based on the climatic conditions to maintain the proper levels of soil moister. A comparison between the monthly irrigation water consumption of the CIS and SIS systems is shown in Table 3. It is clear from Table 3 that using the SIS system, different months required a different amount of irrigation water, unlike the CIS system which used the same amount for the months of July and August as well as the same amount for September and October. While the SIS system used more water during August is used less in September and October. The increase in water consumption in August is due to the higher temperatures during that month compared to July and thus the need for increased irrigation to maintain the proper soil moister. The end result of the implementation of the SIS system was a $5.76 \%$ reduction in the total irrigation water consumption over the four months compared to the CIS system.

Table 3: Comparison of the monthly irrigation water consumption between the CIS and the SIS irrigation systems

\begin{tabular}{|c|c|c|c|c|}
\hline Month & Average temperature $\left({ }^{\circ} \mathrm{C}\right)$ & SIS & CIS base & Savings (\%) \\
\hline July & 38 & 6076.00 & 6076.00 & 0.00 \\
\hline August & 38.5 & 7502.00 & 6076.00 & 23.47 \\
\hline September & 36.5 & 4732.80 & 6000.00 & -21.12 \\
\hline October & 33 & 4273.35 & 5812.50 & -26.48 \\
\hline Total for the four months & NA & 22584.15 & 23964.50 & -5.76 \\
\hline
\end{tabular}

While this might not seem much it is essential to note the impact this had on the vitality of the grass and shrubs. Figure 3 shows the changes in the color of the grass after the implementation of the SIS system. Many spots have shown better results with greener leaves. The yellowish turf grass decreased in lots of spaces enhancing the overall appearance. The bougainvillea, on the other hand, was assessed based on the brightness of its flowers. Figure 4 shows the bougainvillea with no significant difference in the overall appearance or growth, yet more water was conserved by irrigating for a shorter period and a reduction of approximately 3-4 minutes. Note that bougainvillea is a type of plants that need less water when it's grown, and that can be the reason for the less significant impact when managing the irrigation system. 

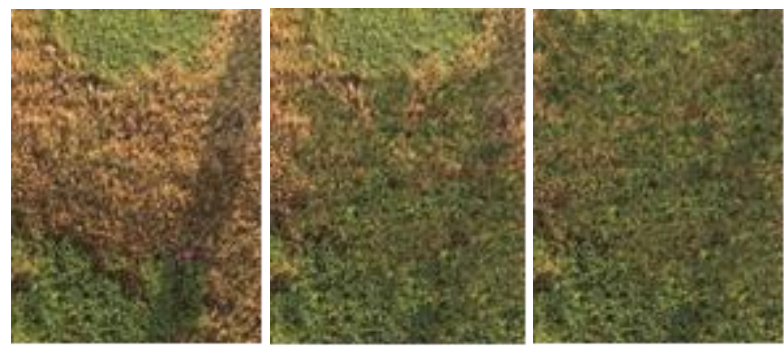

Figure 3: Grass growth during the field experiment using SIS (July on the left and October on the right)

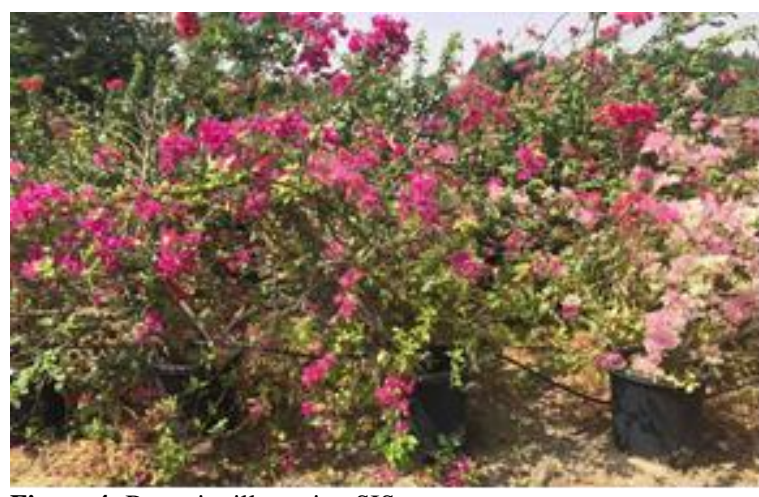

Figure 4: Bougainvillea using SIS

\section{Conclusions}

The focus of this research was to assess the impact of using a Smart Irrigation System (SIS) and comparing it to a timer Controlled Irrigation System (CIS) on the irrigation water consumption and health of the vegetation. The SIS measures the moister content of the soil and determines when and how much irrigation water needs to be supplied in order to save water as well as enhance the health of the vegetation. The study was conducted during the summer months of JulyOctober 2017 at the Warsan Nursery of Dubai Municipality, Dubai-UAE. The results showed changes in the water consumption ranging between $-26.48 \%$ to + $23.47 \%$ with a net reduction of $5.76 \%$ over the duration of the experiment. The SIS also enhanced the health of the vegetation especially the grass.

\section{Acknowledgments}

There is no acknowledgment.

\section{Authors' Contribution}

This paper is based on the MSc dissertation work of Fatma AlSulaimani, which was supervised by Prof. Bassam Abu-Hijleh.

\section{Financial Disclosure}

There is no conflict of interest.

\section{Funding/Support}

No financial assistance was obtained from any organization or company.

\section{References}

[1] Raouf MA. Water Issues in the Gulf: Time for Action. Dubai, Middle East Institute Policy Brief , 2009: 13.

[2] Arozamena RDD. GCC water challneges are an opportunity to lead the world. 2017 [Online] Available at: http://gulfnews.com/opinion/thinkers/gcc-waterchallenges-are-an-opportunity-to-lead-the-world-1.1959369 [Accessed 2705 2017].

[3] Pirani S, Arafat H. Interplay of food security, agriculture and tourism within GCC countries. Global Food Security. 2016; 9: 1-9.

[4] Navarro-Hellin H, Martinez-del-Rincon J, Domingo-Miguel R, Soto-Valles F, Torres-Sanchez R. A decision support system for managing irrigation in agriculture. Computers and Electronics in Agriculture, 2016; 124: 121-131.

[5] Todorovic A, Mehmeti A, Scardigo A., Eco-efficiency of agricltural water systems: Methodological approach and assessment at meso-level scale. Journal of Environmental Management, 2016, 165: 62-71.

[6] Bartlett AC, Andales AA, Arabi. M, Bauder TA. A smartphone app to extend use of a cloud based irrigation scheduling tool. Computers and Electronics in Agriculture, 2015, 111: 127-130.

[7] Ye Y, Liang L, Zhao H, Jiang Y. The system Architecture of Smart Water Grid for Water Security. decision-makers Engineering, 2016, 1554: 361-368.

[8] Shahanas KM, Sivakumar B. Framework for a Smart Water Management System in the Context of Smart City Initiatives in India. Procedia Computer Science, 2016, 92: 142-147.

[9] Osroosh Y, Peters R, Campbell C, Zhang Q. Comparison of irrigation automation algorithms for drip-irrigated apple trees. Computers and Electronics in Agriculture, 216, 128: 87-99.

[10] Dobbs N, Migliaccio K, Li Y, Dukes M, Morgan K. Evaluating irrigation applied and nitrogen leached using different smart irrigation technologies on bahiagrass (Paspalum notatum). Irrigation Science, 2013, 32: 193-203.

[11] Rahman A, Zahura M, Rezwan A. Simplified Design and Fabrication of Water Sprinkler System: A Survey Based Analysis. Procedia Engineering, 2014, 90: 692-697.

[12] Al-Ghobari HM,El Amrazky MSA. Effect of smart sprinkler irrigation utilisation on water use efficiency for wheat crops in arid regions. International Journal of Agricultrue \& Biology Engineering, 2014, 7: 26-37.

[13] Dos Santos M. Smart cities and urban areas-Aquaponics as innovative urban agriculture. Urban Forestry \& Urban Greening, 2014, $20: 402-406$.

[14] Rain Bird SMRT-Y Soil Moisture Sensor Kit". (2017). [Accessed 18 July 2017]. Available at: http://www.rainbird.com/landscape/pr oducts/accessories/smrty.htm.

[15] Atries, E. (2017). [in person]. 2017. 